\title{
AN ALTERNATIVE INDEX FOR QUALITY OF LIFE IN URBAN AREAS
}

\author{
Edward Nissan*
}

\section{Introduction}

In recent years many studies concerned with the quality of life in urban areas have emerged. Notable among these is a work by Boyer and Savageau (1985) entitled Places Rated Almanac, in which 329 American metropolitan areas are rated and ranked according to a grouping of socioeconomic indicators. Boyer and Savageau selected nine indicator categories, each comprised of various factors. The major components were: climate, housing, health, crime, transportation, education, recreation, the arts, and economics. The nine indicators subsequently were merged into a single composite index. Over 35 variables were included in the overall measure by which the metropolitan areas finally were ordered.

The purpose of this study is to provide an alternative procedure for ranking metropolitan areas. The computation utilizes the concept of Euclidean distance. This method allows differences and similarities to be expressed as n-dimensional distances from a composite ideal, where the ideal is chosen as the best score for each factor.

The Boyer and Savageau index is computed by adding the ordinal rankings of the various factors to obtain an average. Pierce (1985) and Norris and Norris (1986) fault the ratings on the ground that such a procedure may produce a measure that is not reliable for comparisons. For example, a ranking of 1 for a specific factor in an area does not mean that the area is ten times as good as an area that is ranked $\mathbf{1 0}$ for the same factor. The distance measure, however, provides an absolute yardstick, and hence preserves the magnitude of the differences. This property allows classifications and comparisons of the areas to be based on accepted statistical considerations.

\section{The Data and Procedure}

The construction of the distance index is illustrated by data taken from Boyer and Savageau (1985). This study considers four of the nine indicator categories: housing, crime, education and economics. Each of these consists of various variables as follows:

*Professor of Economics, University of Southern Mississippi
Housing

Annual average mortgage payment plus property taxes

Annual average utility costs

Crime

Violent crime rate

Property crime rate

Education

Pupil/teacher ratio

Effort index: revenue sharing allotted to supporting the public schools

Academic options in higher education

\section{Economics}

Average household income adjusted for taxes and living costs

Rate of income growth

Rate of job expansion

A composite ideal metropolitan area defined by the pertinent variables is established. The ideal is an area with the most favorable figure for each of the ten variables. For instance, if Atlanta has the lowest average mortgage payment, then this score is taken as the ideal. On the other hand, if Seattle occupies the best position as to the public school student- teacher ratio, then this score is incorporated into the ideal. Though the computed distances are relative to a chosen ideal, the basis of measurement is absolute because it uses a standard yardstick for all comparisons.

Assume that there are $n$ metropolitan areas to be ranked according to $\mathrm{k}$ factors. Let $\mathrm{x}_{\mathrm{ij}}$ be the value that metropolitan area $i$ takes for factor $j$. Since the component factors $x_{i j}$ are expressed in different and incomparable units, they are standardized by using a conventional transformation

$$
z_{i j}=\left(x_{i j}-x_{j}\right) / s_{j}
$$

where

$$
\bar{x}_{j}=\left(\sum_{i=1}^{n} x_{i j}\right) / n \text { and } s_{j}=\left[\sum_{i=1}^{n}\left(x_{i j}-\bar{x}_{j}\right)^{2} / n\right]^{1 / 2} .
$$


The $\mathrm{n}$-dimensional distance, $\mathrm{d}_{\mathrm{i} 0}$, for metropolitan area $i$ from the model metropolitan area 0 is computed as

$$
d_{i 0}=\left[\sum_{j}\left(z_{i j}-z_{0 j}\right)^{2}\right]^{1 / 2} .
$$

By definition of the $d_{i 0} s$, the metropolitan areas with the smaller scores provide a higher quality of life.

\section{Results}

The computation of distances using equation (1) yields scores ranging from a minimum of 8.790 to a maximum of 15.610 with a mean value, $\bar{d}$, of 11.772 and a standard deviation value, $s_{d}$, of 1.079 . For $\bar{d}^{ \pm} 3 s_{d}$, the scores range between 8.535 and 15.009 . Virtually all the distances fall within this range.

A list of the 50 top-rated cities is provided in Table 1. The list is given for four city size classes as follows:

size A: population under 100,000 ,

size B: population $100,000<250,000$,

size C: population $250,000<1,000,000$, and

size D: population $1,000,000$ or more.

Throughout the discussion, the symbols A, B, C, and D represent these defined city categories. The two numbers appearing in parentheses next to the areas are the composite ranks by the distance method and by the method used in the calculation of Places Rated Almanac, respectively. Both rankings are based on the same four factors (housing, crime, education and economics).

Table 2 shows the distribution of the 329 areas and the top 50 rated areas by population categories. City sizes A and $D$ are over represented while city sizes $B$ and $C$ are under represented in the top 50.

Table 3 shows the distribution of the 329 metropolitan areas by clusters. The arrangement is by subsets according to increments of one standard deviation from the minimum distance value of 8.79. The clusters are defined by the values $9.869,10.948,12.027$, and 13.106 . Slightly over one-third of the metropolitan areas fall within the middle range. However, the distribution is not symmetric, favoring in general, scores that fall farther from the ideal.

\section{Analysis}

A statistical examination of the relationship among the four components of the index with the four classes of metropolitan areas is undertaken. Since each of these factors is composed of at least two indicator variables, four separate distance measures by equation 1 are calculated. Each factor becomes the object of analysis in its own right.
For such an examination, a one-way analysis of variance is deemed appropriate. In this case, the primary interest is in whether or not the average distance score for each of the factors, as well as the composite index, differs significantly among the metropolitan classes. The null and alternative hypotheses are

$$
\begin{aligned}
& H_{0}: d_{1}=d_{2}=d_{3}=d_{4}, \\
& H_{2}: \text { at least two } d_{1} s \text { are different, }
\end{aligned}
$$

where $d_{i}$ is the average distance measure for metropolitan size $i$ ( $i=1,2,3,4$ for each factor).

There are five hypotheses, one for each factor (housing, crime, education, economics), and one for the composite index. The rejection of $\mathrm{H}_{\mathrm{o}}$ implies that at least two metropolitan classes differ in their average score for a particular factor. The inequality among the average scores may be attributed for instance to $d_{1}=d_{2}=d_{3} \neq d_{4}$. The Ftest that is used to accept or reject the null hypothesis cannot tell, however, which averages differ from the others. Such a deficiency can be overcome by a method known as multiple comparisons. The procedure is to rank the average scores and then decide whether the scores ranked the lowest differ significantly from each other and from the remaining scores. The Tukey test is selected for this analysis (See Miller, 1986, p. 71).

The application of the F-test for equality of distance scores is rejected for each hypothesis except that for education. This implies that for each of the three remaining factors, at least two metropolitan areas differ as to average score. Application of the Tukey multiple comparisons procedure separates the metropolitan areas into homogeneous subsets (in ascending order of magnitude) as follows: Housing $[(B, A, C), D]$, Crime $[(B, A, C), D$,$] , and$ Economics [(D,A,C), $(C, B)]$.

For housing and crime, the separations are identical. The test cannot distinguish any statistically significant differences among the metropolitan areas of size B, A, and C. However, there is a significant difference between these groups and metropolitan areas D. The implication here is that in the housing and crime dimensions, the areas with populations over one million people are on average farther from the ideal than the other metropolitan categories. On the other hand, in economic terms, areas categorized as D and $\mathrm{A}$ are much closer to the ideal than those in B. Area $\mathrm{C}$ occupies an in-between position.

For education, the acceptance of the null hypothesis implies that the four metro sizes have average index values that are not significantly different. Applying a similar testing procedure for the overall measure, the null hypothesis is not rejected. The test cannot distinguish any statisti- 
Table 1

Top Fifty Rated U.S. Metropolitan Areas, By Population, in Alphabetic Order ${ }^{1}$

Population Under 100,000

$\begin{array}{lrl}\text { Enid, OK } & (1,16) & \text { San Angelo, TX } \\ \text { Middletown, CT } & (49,43) & \text { Sherman, TX } \\ \text { Midland, TX } & (15,254) & \text { Victoria, TX } \\ \text { Pittsfield, MA } & (31,23) & \end{array}$

Population $100,000<250,000$

$\begin{array}{lrlr}\text { Abilene, TX } & (3,10) & \text { Killeen, TX } & (12,1) \\ \text { Billings, MT } & (13,63) & \text { Lafayette, LA } & (10,232) \\ \text { Bradenton, FL } & (21,170) & \text { Longview, TX } & (9,96) \\ \text { Burlington, VT } & (15,7) & \text { New Britain, CT } & (44,80) \\ \text { Charlottesville, VA } & (19,36) & \text { Portland, ME } & (22,42) \\ \text { Danbury, CT } & (35,38) & \text { Portsmouth, NH-ME } & (34,11) \\ \text { Fort Myers, FL } & (27,110) & \text { Sarasota, FL } & (22,188) \\ \text { Fort Walton Beach, FL } & (31,16) & \text { Tyler, TX } & (2,3) \\ \text { Galveston, TX } & (37,183) & \text { Wichita Falls, TX } & (14,72)\end{array}$

Population $250,000<1,000,000$

$\begin{array}{lrlr}\text { Albany, NY } & (31,5) & \text { New London, CT-RI } & (36,25) \\ \text { Austin, TX } & (9,25) & \text { Oklahoma City, OK } & (5,66) \\ \text { Binghamton, NY } & (38,24) & \text { Omaha, NE-IA } & (41,41) \\ \text { Colorado Springs, CO } & (41,162) & \text { Raleigh, NC } & (11,30) \\ \text { Corpus Christi, TX } & (44,104) & \text { Rochester, NY } & (8,30) \\ \text { Hartford, CT } & (41,164) & \text { Shreveport, LA } & (18,61) \\ \text { Jacksonville, FL } & (41,40) & \text { West Palm Beach, FL } & (26,176) \\ \text { Kansas City, KS } & (29,113) & \text { Wichita, KS } & (30,82) \\ \text { Middlesex, NJ } & (17,34) & & \end{array}$

Population $1,000,000$ or more

$\begin{array}{lrlr}\text { Bergen, NJ } & (48,89) & \text { Philadelphia, PA-NJ } & (44,96) \\ \text { Dallas, TX } & (20,125) & \text { Pittsburgh, PA } & (49,32) \\ \text { Houston, TX } & (25,140) & \text { San Antonio, TX } & (27,57) \\ \text { Nassau, NY } & (6,16) & \text { Tampa, FL } & (39,73)\end{array}$

${ }^{1}$ Numbers appearing in paranthesis are the ranks of the metropolitan areas obtained by the distance and Places Rated Almanac methods respectively.

cal differences among the means of the city size groups. It is interesting to note that the ranking of the metro sizes by ascending order is $\mathrm{A}, \mathrm{B}, \mathrm{C}$, and $\mathrm{D}$. The larger the metropolitan area, the farther it is from the ideal, though the differences in their averages are not statistically significant.

\section{Conclusions}

Monetary measures for goods and services, as exemplified by per capita GNP, often are inadequate for measuring human well-being. An important reason is that such measures exclude natural and social amenities derived 
Table 2

Distribution of U.S. Metropolitan Areas, by Population

\begin{tabular}{crrrrr}
\hline \hline & \multicolumn{2}{c}{329 Areas } & \multicolumn{2}{c}{ Top 50 Areas } \\
Size & Number & Percent & Number & Percent \\
\hline $\mathrm{A}^{\mathbf{a}}$ & 30 & 9 & 7 & 14 \\
$\mathrm{~B}^{\mathrm{b}}$ & 140 & 43 & 18 & 36 \\
$\mathrm{C}^{\mathrm{c}}$ & 119 & 36 & 17 & 34 \\
$\mathrm{D}^{\mathrm{d}}$ & 40 & 12 & 8 & 16 \\
\hline
\end{tabular}

-Population under 100,000.

'Population $100,000<250,000$.

'Population $250,000<1,000,000$.

'Population $1,000,000$ or more.

from the place of residence. Quality of life indices can be used to fill this gap.

The selection of the form of the index, the variables needed, and the weights assigned to the variables remain subject to controversy and debate. However, there is no doubt that quality of life indices can be of help to policymakers and government agencies in identifying inequalities based on geographic location.

A common approach to the construction of quality of life indices utilizes socioeconomic data in natural units of goods and services. It is the form of the index that varies. The addition of rank scores and scores standardized from their means are two frequently used methods.

Data from the Places Rated Almanac (1985) were used in this paper to demonstrate the construction of an index based on the concept of distance. This characteristic has several attractive features, the most obvious of which is the establishment of a measure in which all the information contained is comparable. Thus, it is possible toclassify and statistically analyze the results.

\section{References}

Boyer, Richard and David Savageau. Places Rated Almanac. Chicago: Rand McNally \& Company, 1985.

Miller, Rupert G. Jr. Beyond ANOVA: Basics of Applied Statistics. New York: John Wiley \& Sons, 1986.

Norris, Darrell A. and Jean M. Norris. "Places Rated Berated." American Demographics, 8:3(March 1986). 50.

Pierce, Robert M. "Rating America's Metropolitan Areas." American Demographics, 7:7(July 1985). 20-25.

Table 3

Distribution of Metropolitan Areas By Clusters of Index Measure

\begin{tabular}{rrrr}
\hline \hline & \multicolumn{2}{c}{ Metropolitan Areas } \\
Cluster & \multicolumn{1}{c}{ Score } & Number & Percent \\
\hline 1 & $8.790-9.869$ & 13 & 4 \\
2 & $9.869-10.948$ & 63 & 19 \\
3 & $10.948-12.027$ & 122 & 37 \\
4 & $12.027-13.106$ & 99 & 30 \\
5 & $13.106-14.185$ & 32 & 10 \\
Totals & & 329 & 100 \\
\hline \hline
\end{tabular}

